\title{
Title: Media Industries, Work and Life
}

Author: Mark Deuze

Dated: 10 June 2009

Word Count: 4,998 (including endnotes and references)

Working paper, please do not distribute. intended for publication in a forthcoming special issue of the European Journal of Communication.

\begin{abstract}
Convergence culture, as a concept, articulates a shift in the way global media industries operate, and how people as audiences interact with them. It recognizes contemporary media culture as a primarily participatory culture. In turn, this assumption renders notions of production and consumption of (mass, mediated) culture not just theoretically problematic - as has been established earlier in disciplines as varied as communication studies, cultural geography, and media anthropology - but also less than useful on a practical level when making sense of the role media play in people's everyday lives. This paper explores the practical applications of convergence culture from the perspectives of media workers, suggesting not so much the use of "new" categories, but rather an alignment of production, mediation and consumption as constituent practices in all experience of (in) media life.
\end{abstract}




\section{Media Industries, Work and Life}

The media industries, in the broadest sense, can be seen as the key drivers and accelerators of a global culturalization of economies. Media are our window to the world, yet also function as its mirror; media reflect and direct at the same time. Theorizing the way the media industries operate is understanding the elements of the human condition in the information age - living in a world that can be considered a mediapolis: a mediated public space where media underpin and overarch the experiences of everyday life (Silverstone, 2007). As such, the convergence of production and consumption of media across companies, channels, genres, and technologies is an expression of the convergence of all aspects of everyday life: work and play, the local and the global, self and social identity (especially in the use of social networking sites and participation in virtual worlds). The media as cultural industries act as trend amplifiers by flexibly adapting to a globalizing marketplace for products and a global production network for creative labour (Power and Scott, 2004). This perspective builds on a suggestion in my work that media should not be seen as somehow located outside of lived experience - for example as the artefacts we use to connect to each other via internet, or as messages that are transmitted or decoded that may or may not have effects on people, but rather should be seen as intrinsically part of it. Our life should perhaps be seen as lived in, rather than with, media - a media life.

In a way, this point of view differs not much from earlier suggestions, such as Marshall McLuhan's view on media as extensions of man which forms and structures affect how we perceive and understand the world around us, Byron Reeves and Clifford Nass's notion of media as equating real life in terms of how people interact with media as social actors, and Michael Callon and Bruno Latour's insistence on the agency of nonhumans (including computer software, hardware, and technical standards) when studying any kind of social relations. Similarly, authors as varied as Neil Postman, Terje Rasmussen, Stig Hjarvard, and Paul Levinson have developed more or less comprehensive perspectives on media and social theory (Hesmondhalgh and Jason Toynbee, 2008), media ecology (Strate, 2006), and mediatizaton (Lundby, 2009) that supersede the existence of media in a material sense - aiming to explore how changes and developments in society interact with and are "softly" determined by trends in media (production, use, and content). My suggestion is, however, that until recently most of these perspectives were mainly theoretical exercises, with exceptions not necessarily induced from observed and lived experience. In today's media culture, where people increasingly move through the world assembling (more or less deliberately) a deeply individualized media system - in other words: living in their own personal information space - such a viewpoint can form the basis of (empirical) investigation and understanding of everyday life.

A media life perspective unsettles the key organizing categories of the study of communication and the role of media in people's lives: production, content, and consumption. Certainly, the problematic nature of such categories has been argued in the past. One could think of Stuart Hall's notion of media as encoded and decoded with (invariably contested) meanings to challenge a dominant paradigm where mediated messages were generally seen as transmitted; James Carey's equally formidable challenge to the transmission model of communication by emphasizing the ritualistic nature of the way people use media and technology to make sense of 
their world, and the field of media anthropology stressing the linked and circular nature of the production and consumption of culture. Scholars in media studies, informatics, and economic geography similarly have critically articulated the categories of media production and consumption with the parameters of the capitalist (and distinctly cosmopolitan) project, rather than with the material practice or lived experience of how people actually use and make media. Several other terms have been suggested to overcome the perceived production-consumption dichotomy, such as Jesús Martín-Barbero's notion of media as a process where each and every person produces meaning, and Nick Couldry's more recent suggestion of media as practice, explicitly focusing on decentring media research and engaging more deliberately with questions of how knowledge and actions are produced by people through their direct or indirect engagement with media. A media life perspective would assume that people generally do not make sense of their meaning-making processes and usage practices with media in terms of production and consumption. It furthermore aims to discuss media practices less in terms of specific technological affordances, instead opting to see how media in fact are used and appropriated in the organization of everyday life.

Beyond theoretical and operational consequences, a third consideration of a media life/based ontology of contemporary reality can be made regarding the widely suggested convergence of culture and economy in modern life, emblematic of a more networked individualist culture (as Manuel Castells argues), expressive of an increasingly post-materialist society (following the work of Ronald Inglehart and, more recently, Roland Benedikter). This in turn connects to a broad and influential strand of thinking - both in academia and professional fields - regarding the increasing significance of culture in the economy (cf. Jean Baudrillard's suggestion of the signvalue of a commodity predominating its use-value), as well as in politics (articulating a Giddensian primacy of life politics and self-interested engagement over party politics and elections). Néstor García Canclini (1999), among others, observes along these lines a global reconstruction of world culture and local creativity under the paradigms of technology and the market, and advocates vigilance in this process. More concretely, such viewpoints can be linked to Maurizio Lazzerato's critique of the rise of immaterial labour as the new form of work organization in contemporary global capitalist society. Immaterial labour refers to the changes taking place in workers' labour processes in the manufacturing, knowledge and creative industries (including for example journalism and advertising), where time-tested craftsmanship involved in direct labour tends to shift to the currently more privileged yet self-deleterious skills of the information age, involving cybernetics, computers, and mediated communication. Immaterial labour also refers to a parallel process of commoditization of activities that can be roughly labelled as traditionally being part of the realm of social skills: assigning status and building reputations (within specific communities of interest), maintaining and structuring social relations (in teams and networks) - including identity play and performance. Nick Couldry, Göran Bolin, and others have extended these notions to articulate a perspective on immaterial media landscapes - where what is produced by people can be seen as existing increasingly in the realm of views, attitudes, symbols and ideas, yet has direct consequences for social and political realities. This in turn has contributed to an equally recent spatial turn in media studies, emphasizing (the co-creation of) media and space/place relationships (Adams, 2009).

There runs a parallel argument through these and other more or less recent observations about the apparent immaterial, post-materialist, and dematerialized, weightless nature of contemporary society (as in a reduction in the quantity of materials required to serve economic functions, 
including factories, machines, and labor), attributing primacy to the largely informational and symbolic nature of life's processes, which in turn to some extent explains the significance of media as benchmarks for finding and circulating meaning. Indeed, contemporary social theory is suffused with claims making about our increasingly liquid, ephemeral, self-reflexive, mobile, and otherwise less than stable, permanent, or tangible modern times (see in particular Bauman, 2000 and 2007; Urry, 2007). The dissolution of communications' key sense making categories production and consumption - seem to fit nicely within this broader debate, and thus fit within processes of theoretical abstraction about the boundary-erasing nature of contemporary life as well as practical observation of the concurrent exposure to media people enjoy today. The media life perspective engages on both these levels.

In this essay, the study of media industries is considered in a context of what appear to be increasingly complex and boundary-breaking relationships between media companies, media technologies, media producers and consumers - what Henry Jenkins (2006) describes as a convergence culture. This particular approach is presented here as flowing from a more abstract appreciation of the role of media in everyday life as people's lives are seen as lived in media - an ontological turn that presumes to build on and perhaps extend many existing theoretical, operational, and organizational debates about the structure and conditions of contemporary existence as described, however briefly and insufficiently, above.

In the current convergence culture - within which all media industries operate - the key question for theorizing media industries must be how we can adequately explain the process, content and consequences of consumption and production when people's contemporary media practices seem to include both at the same time. Further, the blurring of real or perceived boundaries between makers and users in an increasingly participatory media culture challenges consensual notions of what it means to work in the media industries (Deuze, 2007). This convergence can be seen as driven by an industry desperate for strong customer relationships, technologies that are increasingly cheap and easy to use, and a media culture that privileges an active audience (Turow, 2005). After considering more or less traditional theories of media industry studies - looking at the political economy of the industry and considering the different roles of audiences - I develop convergence culture as a third perspective. Although this perspective allows for a more mixed, hybrid, and complex understanding of the roles, functions and work of media industries in society, it is not without problems - particularly regarding the co-optation of all creativity by corporations, and the colonization of consumer/producer agency by markets (Deuze, 2009). After these critical considerations, the essay concludes with discussing possible consequences for further research.

\section{Media Industries and Society}

Beyond the crucial role media industries play in everyday life and the significance of their products and production networks in the global marketplace, another reason for carefully examining the media business and its workers is its influence on the cultural economy of contemporary cities. Cultural and creative industries tend to cluster close to certain urban regions - such as Los Angeles, New York, Vancouver, Brisbane, Milan, Wellington, Munich, and Manchester - and thus catalyze a flurry of economic, cultural, and social activities in those regions. This, in turn, has led many local and regional governments to invest in public relations campaigns, profiling themselves as creative or media cities. Creative industries are attracted to, 
and attract investors and generate business for restaurants, clubs, theatres, galleries, and other ingredients of cultural and economic life. Media thus are not only central to an understanding of everyday life in terms of the aesthetic quality and the utility they bring to information, entertainment and communication. The media are also key to analyzing the converging economic and cultural environment of the world's post-industrial urban spaces. Much of the work in the media industries is interconnected on a global scale through international co-production, outsourcing, offshoring, and subcontracting practices. Combined with their role as accelerators of urban regeneration, these interconnected creative clusters contribute to a shift in power away from states and national territories to a transnationally converging cultural economy and economy of culture (Du Gay and Pryke, 2002).

Whereas the media industries generally operate on the premise of aggregating audiences for advertisers (while assuming to provide people with something in return for their work as audiences, such as services like news, information, entertainment), today the audience is not just a mass market to transmit messages to - it is also an increasingly segmented and fragmented public to collaborate with in the co-creation of content and experiences. Among creatives and brand managers in many if not most ad agencies the contemporary focus is on interactive advertising, which can defined as the paid and unpaid presentation and promotion of sponsored products, services and ideas involving mutual action between consumers and producers (Leckenby and Li, 2000). Marketing communicators brainstorm about the potential of "social", "upstream" or even "spherical" marketing (Svensson, 2005), which refers to the strategic process of identifying and fulfilling consumer needs early in product development, up to and including customers and users at various stages in the total production and product innovation cycle. In journalism, editors of news publications actively consider adding what is called "citizen journalism" to their Websites, allowing members of the audience to respond, comment, and submit their own news. In particular, convergence culture has been part of the organization of work in the computer and video game industries. Game publishers often consider their consumers as co-developers, where product innovation and development largely depends on online consumer communities. In the music and recording industry, both mainstream bands like Radiohead and Nine Inch Nails, as well as so/called "indie" acts on a local level sidestep traditional cultural intermediaries such as record labels to directly interact, and collaborate with fans online (for example in terms of album cover design, concert set lists, mixing and remixing processes, and even album pricing). Media industries increasingly make use of this generally "productive" consumer behaviour, which means that the role of creative labour and the management of cultural production taking place within such organizations is becoming increasingly complex as well. The ongoing merger of production and consumption across the various media, cultural, and creative industries signals the emergence of a global convergence culture, based on an increasingly participatory and interactive engagement between different media forms and industries, between people and their media, as well as between professional and amateur media makers.

In short, when conceptualizing media industries, one is struck by the simultaneous occurrence of many instances of what we could call convergence:

- convergence of place, as in the sites of media production;

- convergence of identity, as in notions of professional identity versus the "cult of the amateur" (Keen 2006); 
- convergence of experience, as in the way people interact with, give meaning to, and even actively make their media as a window to the world.

\section{Media Industries and Work}

The ecosystem of media organizations consists of a combination of (large and small) public service and for-profit companies dealing with the industrial and creative production and circulation of culture. In terms of media work, this culture refers not only to the production of spoken and written words, audio, still or moving images, but (and increasingly) also to providing platforms for people to produce and exchange their own content. In contemporary definitions of what the work within these industries involves, four elements tend to get mixed up, which to some extent makes an adequate assessment of media industries rather difficult: content, connectivity, creativity, and commerce - which all translate into the production of culture. Media industries produce content, yes, but also invest in platforms for connectivity - where fans and audiences provide free labour (Terranova 2000). Media work is culture creation, yes, and it tends to take place within a distinctly commercial context.

As argued before, in the current digital and networked global media ecosystem the roles played by advertisers, media producers, and content consumers are converging. Through the widespread use of these networks the boundaries blur not only between geographical regions (households, cities), and between types of regions (local-global) and domains (private-public), but also between the dimensions that constitute regions themselves - such as material, symbolic and imaginary spaces (Falkheimer and Jansson, 2006). The production system of the media industry is a case in point, as it has become networked on a "translocal" scale, integrating different locales of cultural production into a global production system, integrating and localizing cultural values and regional symbols across dispersed markets. Many industries - such as computer and video game development, motion pictures, and television - offshore, subcontract and outsource various elements in the production process to save costs and redistribute risks. Examples are securing international co-financing deals for television projects, filming and post-producing a movie at several locations (often in different countries), moving an editorial division or marketing department of a news organization to another part of the world (a practice called "remote control journalism"1), mixing music recorded in Los Angeles in a studio outside of London, localizing game titles set in one regional, cultural or national context in another part of the world, adding local soundtracks and hit songs to generic advertising campaigns generated for global brands, separating out the marketing and distribution of titles, and so on. It is important to note that within these networked forms of production people generally do not move across borders - ideas, skills, and values do. In this sense the globalization of production networks in the media industries can be considered a supercharged example of the broader trends in the mutual construction of social, and spatial relationships in and through media.

In terms of media work, then, convergence relates to:

- the inclusion of various stakeholders - professional producers, audiences, sources, sponsors - in the (co-) creation of media content and experiences;

- the integration of various media industries in a global production network;

- the immaterialization of media production practices - as skills, values, and ideas rather than people or machines move across such networks; and 
- the coordination between distinctly different goals - creativity, commerce, content, and connectivity - in the media production process.

\section{Convergence Culture}

In today's digital culture, media work can be seen as a stomping ground for the forces of increasingly differentiated production and innovation processes, and the complex interaction and integration between work, life, and play, all of which get expressed in, and are facilitated by, the rapid development of new information and communication technologies. This convergence is not just a technological process. Media convergence must also be seen as having a cultural logic of its own, blurring the lines between economics (work) and culture (meaning); between production and consumption; between the competition and cooperation ("coopetition") implied in creativity, commerce, content, and connectivity; between making media and using media; and between active or passive spectatorship of mediated culture.

When combined with ongoing efforts throughout the media industries to develop multimedia formats (either through mergers and integrating different company units, or by the increasingly popular networking of the production process across numerous subcontracted business partners), producer-consumer convergence poses significant challenges to theorizing media industries. Traditional frames of reference interpret these trends from distinctly different perspectives, looking at either the industry (political economy) or the audience (reception analysis). As mentioned earlier, the literature for some time now has clearly signalled the reductionist and ineffective nature of such approaches (see also: Jenkins and Deuze, 2008).

One way that the increasing use of user-generated content in professional media production can be seen is as an example of the global media industries' attempts to secure, harness, and thus win back control over the circulation and consumption of culture. It can thus be viewed as evidence of the increasing rationalization and (thus) homogenization of all forms of public communication (including news and entertainment) in the hands of fewer and fewer multinational companies. However, such a traditional political economy of industry belies three contemporary developments in the structure and organization of media industries: vertical disintegration (partly because of failed synergies), media deconcentration, and outsourcing.

Although most of the major media corporations and production businesses consolidated their holdings into large corporate conglomerations in the 1990s, a parallel development of media deconcentration and corporate dysfunctionalism have been recorded at the same time. Research in various media industries consistently suggests that infighting and turf wars, slow centralized decision-making processes, mismanagement, difficulties of building or sustaining a knowledgesharing work culture, as well as a general lack of cooperation among different media properties within the same corporation or holding firm are among the key reasons why mergers or efforts towards achieving synergies in the cultural industries generally fail or do not deliver the expected results. Partly in a response to these failures, but also in an attempt to develop flexible strategies to cope with increasingly unpredictable and complex markets, a trend toward flexibilization of production and labour is accelerating throughout the media industries, which in turn signals less power over the creative process flowing from large media conglomerates, and increases cocreative relationships between media professionals inside and outside of firms, as well as between consumers and producers of media. Whether in the movies, advertising, in journalism or video 
game development, most of the work in these industries is done by independent contractors, loosely affiliated teams, temporarily hired work groups, or otherwise contingently employed labour, often spread across translocally situated contexts (Hesmondhalgh, 2006). The roles of all those companies, networks, and individuals in the creative process of the media industries converge (and diverge) in countless unpredictable, confusing and complex ways. My reading of the industry perspective on convergence culture does not assume large corporations control all aspects of the production of news or entertainment. However, neither has the global market completely opened up to hundreds of thousands of small or independent companies. This complex and symbiotic two-tier production system runs throughout the cultural and creative industries, where independent companies can be under long-term contract of corporations, and where the same multinational companies can completely outsource production or acquire a show or movie after production elsewhere, and where ownership of different media properties has a tendency to change quickly.

Not only does this perspective on convergence culture from the view of the industry offer us a more complex, hybrid and colourful palette for looking at the production of culture, it also opens the door to include the audience, the consumer, and the user into our framework for understanding the collisions and collusions of "old" and "new" in the contemporary media ecology.

The extent to which this convergence culture plays a significant role in the entire media ecology, including and interpellating the audience as a productive force in the creation and circulation of culture, can be illustrated by countless studies (for example in Europe conducted by the OECD, and in the US by the Pew Research Center's Internet \& American Life Project) suggesting today the majority of people make media when they use media (including but not limited to maintaining a blog; creating or working on a personal webpage; sharing original content such as artwork, photos, stories, or videos online; and remixing content found online. Media co-creation furthermore takes place in perhaps more modest terms, ranging from the customization of media devices (ringtones, wallpapers, screensavers, channel programming) to the often passionate production of fan movies, citizen journalism sites, online video mashups, and computer game modifications (or "mods"). It must be clear that contemporary citizen-consumers demand the right to participate - or at the very least are constructed as such across all media industries.

With the gradual development of industrial standards and financially successful practices for media companies embracing audiences as co-creators of content, a glimpse is offered on the possible outcomes of the suggested convergence between sender and receiver from the perspective of the industry. Considering the corporate enclosure of the information commons, one has to note the triangular tactics of increasingly enforced restrictive regulation of copyright as a form of property, disintermediating practices of soliticiting users' free labour in the creative process, and opaque uses of social media to establish new ways of "taming" or controlling the otherwise unpredictable behaviour of consumers. This is not to say that internet users step blindly into such traps, nor that when they do, companies are necessarily successful in harnessing their creativity. Indeed, the strategic or tactical opposition among certain individual or groups of users to some extent feeds into the deliberate construction of consumers as "unpredictable masses" by the contemporary mainstream in marketing and corporate communication. A traditional audience perspective would focus on the behaviour of audiences as either successful consumers, or as active in a strict sense of meaning-making. In a context of convergence culture, one could add a 
more explicit reference to emerging read/write multimedia literacies (Hartley, 2007) with a necessity to articulate legal rights and protections for the producing consumer - what Aoki (1993) has described as audience "recoding" rights. Such approaches seem to be more responsive to the emerging complex relationships between media industries, their producers and the consumers. ${ }^{\text {ii }}$

\section{Discussion}

This essay has suggested how convergence culture takes place on both sides of the media spectrum: production and consumption. Within this spectrum, the distinctions between the traditional role-players in the creative process are dissolving. The key to understanding the currently emerging relationships between media consumers and producers, or between media owners and media workers (whether paid or voluntarist), is their complexity. These relationships are constantly reconfigured in a convergence culture, and at times are both reciprocical and antagonistic. Such liquid relationships are seldom stable, generally temporary, and at the very least unpredictable. Lev Manovich (2005) calls this a "culture of remix and remixability," where user-generated content exists both within and outside of commercial contexts, and supports as well as subverts corporate control. While this may be true, it is safe to say that professionals -and the companies that employ them are better protected and more powerful in negotiating terms of service than the average consumer is. The work that citizen-consumers do as part of what Von Hippel calls "user-innovation communities" (2005: 103ff), operating in a system of what Benkler describes as "commons-based peer production" (2006: 60), is at least in part dependent on, contingent with, and benefiting to the market-driven efforts of the multinational media enterprise.

Faced with intense competition, an increasingly critical and unpredictable user, and heightened commercial pressures from a global market, media companies dismantle their production operations into a flexible global network of temporary affiliations in order to focus more on controlling distribution and access in a context of increasingly precarious labour conditions for media workers, At the same time, the audience seems to be quite content with on the one hand spending more time with media than ever before, while at the same time repurposing, remixing, and creating their own media in the process. Media technologies contribute to converging the industrial and creative processes associated with both these trends, and suggest in their generally networked, remixable, customizable and portable form the need for a perspective on media production and consumption that is both aware of the interchangeable nature of these categories, and manages to articulate these artefacts and activities with broader arrangements in contemporary society. Jenkins' notion of a convergence culture can thus be seen as a fascinating case study to articulate broader concerns about the categories, perspectives, and paradigms in the field of media and communication studies. With the media life framework as briefly explored at the outset of this piece, I hope to have offered a possible entry for this discussion. It is certainly one that I intend to explore further. 


\section{References}

Adamas, Paul C. (2009) Geographies of Media and Communication. Somerset: Wiley-Blackwell. Aoki, Keith (1993) Adrift in the intertext: authorship and audience "recoding" rights. ChicagoKent Law Review 68.

Balnaves, Mark, Mayrhofer, Debra, Shoesmith, Brian (2004) Media professions and the new humanism. Continuum: Journal of Media \& Cultural Studies 18(2), 191-203.

Bauman, Zygmunt (2000) Liquid Modernity. Cambridge: Polity Press.

Bauman, Zygmunt (2007) Liquid Life. Cambridge: Polity Press.

Benkler, Yochai (2006) The wealth of networks. New Haven: Yale University Press.

Canclini, Néstor García (2001) Consumers and citizens: globalization and multicultural conflicts. Minneapolis: University of Minnesota Press.

Deuze, Mark (2007) Media Work. Cambridge: Polity Press.

Deuze, Mark (2009) Convergence Culture and Media Work. In: Perren, A., Holt, J. (eds.), Media Industries: History, Method, and Theory. Malden: Blackwell.

Du Gay, Paul, Pryke, Michael (eds.) (2002) Cultural economy: cultural analysis and commercial life. London: Sage.

Falkheimer, Jesper, André Jansson (eds.) (2006) Geographies of Communication: The Spatial Turn in Media Studies. Göteborg: Nordicom.

Hartley, John (2007) 'There are other ways of being in the truth': The uses of multimedia literacy. International Journal of Cultural Studies 10(1), 135-144.

Hesmondhalgh, David (ed.), (2006) Media Production. Maidenhead and Milton Keynes: The Open University Press.

Jenkins, Henry (2006) Convergence Culture: where old and new media collide. New York: New York University Press.

Jenkins, Henry, Deuze, Mark (2008) Convergence Culture. Convergence 14(1): 5-12.

Keen, Andrew (2008) The Cult of the Amateur. New York: Broadway Business.

Leckenby, John, Li, Hairong (2000) Why we need the Journal of Interactive Advertising. Journal of Interactive Advertising 1(1). URL: http://www.jiad.org/vol1/no1/editors/index.htm.

Lundby, Knut (ed.) (2009). Mediatization: Concept, Changes, Consequences. New York: Peter Lang.

Manovich, Lev (2005) Remixability. October-November 2005. URL: http://www.manovich.net/DOCS/Remix_modular.doc.

Power, Dominic, Scott, Allen (eds.) (2004) Cultural industries and the production of culture. London: Routledge.

Silverstone, Roger (2007) Media and Morality: On the Rise of the Mediapolis. Polity Press, Cambridge (UK).

Strate, Lance (2006) Echoes And Reflections: On Media Ecology As a Field of Study. Hampton Press.

Svensson, Göran (2005) The spherical marketing concept: A revitalization of the marketing concept. European Journal of Marketing 39 (1/2), 5-15.

Terranova, Tiziana (2000) Free labour: producing culture for the digital economy. Social Text $18(2), 33-57$.

Turow, Joseph (2005) Audience construction and culture production: marketing surveillance in the digital age. The Annals of the American Academy of Political and Social Sciences 597, 103-121.

Urry, John (2007). Mobilities. Cambridge: Polity Press. 
Von Hippel, Eric (2005) Democratizing innovations. Boston: MIT Press.

\section{Endnotes}

\footnotetext{
${ }^{\mathrm{i}}$ See URL: http://deuze.blogspot.com/2006/11/remote-control-journalism.html.

ii The culturally convergent practices of media industries, remixing professional content and usergenerated content in the creative process, led The Economist (of 20 April 2006) to ask the fundamental question: what is a media company? Traditionally, media companies would be seen as audience aggregators: engaging in the production of content aimed as mass audiences. Considering the social, technological and economic trends outlined above, such a definition has become problematic. Instead of "audiences," media businesses today talk about "networks," emphasizing media work as a practice that would (or should) generate endless opportunities for people to form communities of interest around content. This creates interesting dysfunctional family-effects within large media corporations, where some parts of the firm are actively restructuring to meet the demands of what The Economist describes as a race to become "the most liquid media marketplace, "ii while other sectors of the company are still very much in the process of developing intricate Digital Rights Management (DRM) software intended to prevent all this arguably profitable audience activity from actually taking off (Benkler 2006).
} 